\title{
An Understanding of Language Development Models-Pidginization from the Perspective of Chaos Theory
}

\author{
Guodong Zhao \\ Foreign Languages Department of Inner Mongolian Finance and Economics College \\ Hailaer Street 47. Huhhot, Zip code: 010051 China \\ Tel: 86-471-366-1487Ｅ-mail: zhaoliu1116@163.com
}

\begin{abstract}
With the accelerated globalization, domestic and international communications become more frequent than ever before. As the major media of international communication, languages contact with each other more actively by day. And in the active contact any language would gradually develop and change. Pidgin language is a unique linguistic phenomenon resulted from the frequent language contact. By taking pidgin as an example, this article attempts to shed some light on the language development models in the frequent contact and how one language reacts to its environment, which includes a foreign language, a new culture and new information. With "Chaos Theory" brought to the horizon, this paper figures out three ways, namely, to progress, to decay, and to remain untouched, for any language to choose from when it is in contact with a new environment.
\end{abstract}

Keywords: Pidgin, Language Contact, Environment, Complexity

\section{Introduction}

In 1863, August Schleicher formulated his theory of the Family Tree of Language, and thus he started the famous Evolutionists view of human language. This was a big stride in the field of linguistic study. But Family tree theory was not reliable in interpreting the way language develops, because firstly, Family tree theory does not allow convergence of different languages; however language convergence is an unquestioned social phenomenon today; secondly it seems that language bifurcated at a certain time in history suddenly, while in reality language change is a very common happening people can witness almost everyday; thirdly, this theory puts emphasis on the linear development of language rather than the interrelationship between different languages for example English, Latin and French, but a lot of evidence, for example loanwords and borrowings, show that language change is resulted to a certain extent from language contact; at last, Family Tree Theory idealized the uniform speech communities, but in fact everyone is speaking a dialect.

Later the structuralists put forward the structuralist view of language by treating language as closed structure of words and rules, independent from its environment. This idea is not sound enough either, for any language is a part of the whole system of society and language often reacts to the stimulus from the complexity of the system. The founder of modern linguist Saussure wanted to establish the autonomy of linguistics, freeing it from reliance on other factors. But language is so involving and so closely related to the environment that any language could not undergo a slight change without relying on some force from outside.

Chaos Theory is a set of theories and methods developed in different disciplines to understand and research complex, dynamic systems and non-linear development of these systems. Being open and able to self-organize are the features of the theory. Chaos, with reference to chaos theory, refers to an apparent lack of order in a system that nevertheless obeys particular laws or rules.

Pidgin language is a contact language with unique linguistic features. Decades ago, no light was shed on it for there seems to be no means by which to explain it fully. From the perspective of Chaos Theory, pidgin can be well explained as a third way a language reacts to the environment. To understand pidgin language in this angle, it is advisable to start with the analysis of language development.

\section{Language Development Model}

\subsection{The Family Tree Model}

The evolutionist's study of linguistic development in history concerns mainly about the Indo-European languages as is shown in the Table 1. Languages like Chinese are excluded from this model. It is easy to imagine that English and German have a lot in common in that they are both derived from the same parent language. A lot of English words have their counterparts in German, and the counterparts display similarities to the English words. For example: 


$\begin{array}{llcc}\text { German } & \text { English } & \text { German } & \text { English } \\ \text { Artikel } & \text { article } & \text { lernen } & \text { learn } \\ \text { Ball } & \text { ball } & \text { studieren } & \text { study } \\ \text { Bier } & \text { beer } & \text { kommen } & \text { come } \\ \text { Familie } & \text { family } & \text { hören } & \text { hear } \\ \text { Literatur } & \text { literature } & \text { bilden } & \text { build }\end{array}$

These phenomena show that the similarities between "sister languages" are due to the same origin. But by examining the vocabulary of French and English, we can still find almost the same circumstance. Moreover, we can find some words in Chinese which demonstrate the influences of English, such as "Safa", "tanke", "kafei", "kekoukele", "youmo", "balei", "qiaopai", "VCD", "GDP", which is also the case in English, for instance, "kang", "taiji", "qigong", "tea", "China", and these words are from Chinese.

The findings above illustrate that language not only develops vertically, but horizontally. In reality, we still can find that many cases like loanwords, borrowings, transliterations and blending do exist in every language, no matter how far away these languages are in origin from each other, which is contradicted to the Theory of Family Tree formulated by August Schleicher. The Family Tree Theory put emphasis on the linear relationship of languages, and it does not allow language convergence as is shown in table 2, even the languages like D and $\mathrm{E}$, which may be quite close to each other in geographical relation, could never come into terms with each other. But even the most irrelevant two languages are now starting to infiltrate into each other one way or another. Language is no longer isolated from its environment due to the fast pace of globalization; Languages contact becomes inevitable.

The evidence above reveals that the Theory of Family Tree of Languages has its limitations. It cannot objectively illustrate the actual change of language by taking every aspects of the environment into consideration. Language frequently reacts to its environment through absorbing new information and adapting to new situation. A good case in point is the English language. The Old English adopted a lot of Latin words in its interrelation with Latin after the Romans conquer. Later, the old English again borrowed a lot of words from French after the Norman Conquest. The simile language change occurred so far as many other languages are concerned. So, it can be concluded that language exists in a system of complexity, and language frequently react to the influences of this system in various ways.

\subsection{The Structuralism's View on Language}

In the early 20th century, the Swiss linguist Ferdinand de Saussure, by developing the comparative methods, put forward the structural model, which started the modern linguistics and was a great revolution in the field. According to this theory, language is a structure made up of words organized according to certain rules. Language development is a linear development independent of the environment. Linguistics is an isolated discipline, which has nothing to do with other fields.

This theory cannot explain the actual model of language because it depicts language in a 2-dimension way, which contains only words and the grammar of language, without taking the external aspects into consideration.

In reality, language cannot survive without social and environmental soil. Foreign language learners would easily find the cultural and social traces in the vocabulary of the language. For example, English language contains a lot of words and idioms related to the sea, which could be explained as England is a nation on islands; the language of this nation is affected by its location; Arab, on the contrary, is a nation on desert, so, in Arabian language, there must be a lot of words describing desert and camels, which have been proved true. See table 3

If this model tells the truth of language, a language learner could master any language when he or she has the knowledge of the grammar and vocabulary of that language. This may be true to the native language learners. When it comes to the second language learning, we find that a person with a large vocabulary and a good command of the grammar of the second language dose not necessarily use the language well, which is often the biggest obstacle for any second language learner (SLL).

It is easy to be accepted that language is three-dimensional. Basically, the whole universe is three dimensional, and language is one part of the universe, we would simply draw such a conclusion that language is a 3-dimension body with its own internal organization and the external relations to the universe, as is shown in Table 4.

In a whole, language is not a linear structure of words and rules, but a system of complexity, where each element 
has its own organization and influences each other. This model is what the Chaos Theory describes as the "complexity".

\subsection{Modern Linguistics and Chaos Theory}

Chaos Theory is set of theories and methods developed in different disciplines to understand and research complex, dynamic systems and non-linear development of these systems. Complex systems are more than the sum of their components, are open towards their environment and have the ability of self-organization. With the development of Chaos Theory our knowledge about complex system, their actions and reactions and their internal structure will increase. In many disciplines Chaos theory and its discoveries are successfully applied.

According to the Chaos Theory, language is a contributor of a complexity. Language development is not an isolated, independent and linear process, but demonstrates the nature of the complexity. The new model of language development is not a tree-like model, but a river delta web with different branches interrelated with each other, which can be shown in Table 5 below. So language change is a much-involved process, in which both the historical development of the language and the horizontal relationship between this language and other cultures and languages contribute a lot to the process. The study of language change cannot be carried out without taking these two aspects into consideration. And accordingly the synchronic study of any language should involve not only the study of the characteristics of one language, but also the relations between this language and other languages. Language contact, one very common linguistic phenomenon, which was once ignored by some linguists, now gradually draws the attention of many researchers. See Table 5

\section{Language Contact and Pidgins}

\subsection{Two Attractors: Strive for New Information and Cling to Tradition}

With language contact as a prerequisite of this research based on the Chaos Theory, two important attractors, namely "strive for new information" and "cling to tradition" are introduced into broad light. Being exposed to the environment, a language has mainly two ways to go - progress or decay. It may generate into a higher level of development by adjusting to the new environment, or it may become obsolete and backward because it can hardly keep pace with the time. But there is still a third way to go. It may remain untouched by the new environment but reacts to the environment by taking a mid-way measure.

Due to frequent social contact, a language may inevitably be exposed to a lot of new information. If the language is quite open enough, and it is ready to deal with the new information in an active manner, a lot of new words and expressions will get into this language step by step and finally become a part of the vocabulary of this language. In this case, the force of "strive for new information" of this language is strong, and this language will generate into a higher level of development. This is the first and the most active way in handling language contact. With a large number of new words being absorbed into the language, the morphology and phonology of this language will undergo certain changes, and the new vocabulary from another language will also be modified so that it may easily accepted by the language communities in the target language. A very good case in point is the Old English (OE for short). The OE had lost a lot of its own words and absorbed few thousands words mainly from French, Latin and the languages of other low countries. In this way, the OE gradually generated into Middle English with many loanwords and borrowings, but it was still English. So, from the formation of the vocabulary of English in history we can find the clear clue to the horizontal relationship between English and its environment.

However, if a language is not open enough, or not ready to absorb the new information, it will react to the influences of the environment very passively. At this time, the second way is taken. Facing large amount of new information, this language may directly reflect the input with regular feedback and cling to the tradition. Thus, the vocabulary of the language would be out-of-date for it cannot meet the need of social development. But in order to keep pace with the time, many members of this language community would turn to speaking foreign languages in order to communicate with the people beyond their nation. In the long run, with fewer people go on speaking their own language, this language will gradually lose its front in the fierce competition if no measures are taken to save their language from degenerating. And in reality some languages of the minority groups develop in this direction. Fortunately, actually no language today is absolutely closed or completely open. Being closed or open is a matter of degree instead of a matter of quality.

\subsection{Pidgins, A Mid Way to Go}

Quite often, the above two attractors would form balance. If one national language community (for instance English people) come into terms with one native language community (for instance Chinese) for economic interests or political necessity, but they are reluctant to learn or speak the native language because they feel the 
superiority of their own language, however, the native language speakers have no interest in learning English because they believe they are least benefited from the communication with this English speaking community, but they are forced to learn to some extent, a balanced situation will emerge. In this case, English speakers will make concessions on their language so as to break the dilemma. They would simplify their language so that the native speakers can easily accept it. The native speakers, on the other hand will accept the simplified language by adopting some phonological, morphological and syntactical patterns of their own language in the new language. Finally a language of blending — pidgin language comes into being. And this is the mid-way taken between the above two ways.

\section{Pidgins, A Special Way in Handling New Information}

\subsection{The Forming of Pidgin}

The words pidgin is derived from the Chinese inaccurate pronunciation of the English word "business". Pidgin is a special linguistic phenomenon in many parts of the world other than China. The forming of pidgins in different places displays different characteristics. It is very difficult to define the forming of the special language. But by examining many pidgins in history, Holm presents such an explanation:

"A reduced language that results from extended contact between groups of people with no language in common; it evolves when they need some verbal communication, perhaps for trade, but no group learns the native language of the other language for social reasons that may include lack of trust or of close contact."

The Chinese linguist Ye-Baokui states that pidgins refer to the languages form by mixing different natural language elements in the areas of frequent contact. Ralph Fasold puts it this way: "Roughly a pidgin language is generally understood to be a simplified language with a vocabulary that comes mostly from another language".

From the definitions presented by the linguists above, a conclusion could be drawn that pidgin is a contact language. It is special in that it concerns the contact of two or more completely different languages. These languages bifurcated, if the did, at a very early time in history. According to the Evolutionists' view, convergence is almost impossible, not mentioning two completely different languages far away from each other in the family tree. But actually, pidgin gives us a good example of language contact, especially the contact between two obviously different languages. This situation illustrates that language exists in a system of complexity and reacts to this system actively.

\subsection{Characteristics of Pidgins}

The uniqueness of the pidgins lies in how they cope with the new information. Most pidgins were formed from the colonization. "To be specific, pidgins are typically formed in trading and plantation situations in which speakers of one language need to communicate with speakers of another language in a limited way. Under either circumstance, the speakers of both languages are not equal economically and socially. Furthermore, the two languages have distinctive cultural backgrounds. So each party is not willing to accept other's language. To either speaker, the other language is new information. It is necessary to create a new variety out of two or more existing languages, and this process is pidginization, or just as William A. Foley put it "a cultural contact induced change".

From the perspective of sound, for the convenience of the economically inferior language speakers, pidgins are likely to be fewer and less complicated in their possible arrangement than those of corresponding standard languages of the economically superior groups. For example, after the Opium War in China, owing to frequent contact with foreigners, a English-based Chinese pidgin was developed in Shanghai. Pidgin words of this kind like "kangbaidu" (comprador), "lasika" (last car, referring to the last one), "heluosanmu" (all same), "wentaoluo" (one dollar), "kangbaiyin" (combine), "namowen" (number one) are comparatively easy to pronounce, but the meanings are mostly English.

The morphological and syntactical structures of the words are also simplified. A pidgin is lack of inflectional endings in nouns, verbs, pronouns and adjectives. The complicated syntactical structures like the clauses are also out of sight in pidgins. All these are concessions made by the socio-economically dominant language. Ye-Fei sheng etc. take Tok Pisin as an example to show the morphological characteristics of pidgins in the book An Outline of Linguistics. Without the inflectional endings, a pidgin language is not as flexible as the dominant language, so outflanking is a common method in description. For example, "grassbelong face" refers to mustache; "jump inside" means surprised; and "inside tell him" means thinking.

The characteristics of pidgins discussed above demonstrate the mid-way measure taken by one language in coping with new information. The unique way a language deals with new information shows that language contact is possible and universal regardless of the distances between the language communities or between the 
languages themselves.

\section{Where to Go, Pidgin?}

Pidgin is a language with no stable speakers. It is an agreement reached by two or more parties for special reason. The future of pidgin languages is unpredictable. If the two or more parties don't come into terms with each other, the language is put aside. If a pidgin can get a large population who speak the pidgin as their mother tongue, the pidgin will become a Creole. This is a diachronic phenomenon that involves a process from quatitive change to qualitive change.

\section{Conclusion}

Pidgin is a unique language phenomenon different from the ordinary language varieties. The special feature of pidgin - unpredictability, is a manifestation of Chaos Theory in application. The analysis of the form and the characteristics of pidgin shed some light on the basic model of language development. Language contact is inevitable, but how to react to the influence coming from the environment will determine the future of a language. With such awareness, a language community will consciously take corresponding measures to cope with the system of complexity so that their language could not only survive, but also keep pace with the time.

\section{References}

Albert C. and Baugh, Thomas Cable. (2001). A History of English Language. Beijing: Foreign Language Teaching and Research Press.

J. M. Aitchison. (1981). Language Change: Progress or Decay? London.

William A. Foley. (2001). Anthropological Linguistics: An Introduction. Blackwell Publishers Ltd,.

Ronald Wardhaugh. (2000). An Introduction to Sociolinguistics. Foreign Language Teaching and Research Press.

Ralph Fasold. (2000). The Sociolinguistics of Language. Foreign Language Teaching and Research Press.

R. A. Hudson, Sociolinguistics. 2nd edition. (2000). Foreign Language Teaching and Research Press.

Diane Larsen-Freeman and Michael H. Long. (2000). An Introduction to SLA Research. Foreign Language Teaching and Research Press.

Holm. (1988). Pidgins and Creoles. Cambridge University Press.

Gregory Rae, Chaos Theory: A Brief Introduction. [Online] Available: http://www.imho.com/grae/chaos/chaos.html (May 22, 2006).

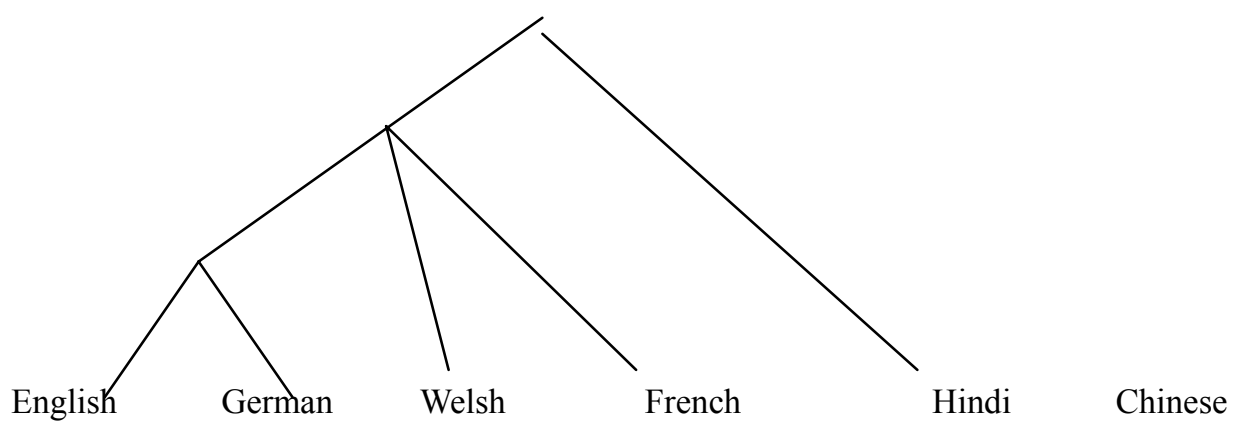

Figure 1 


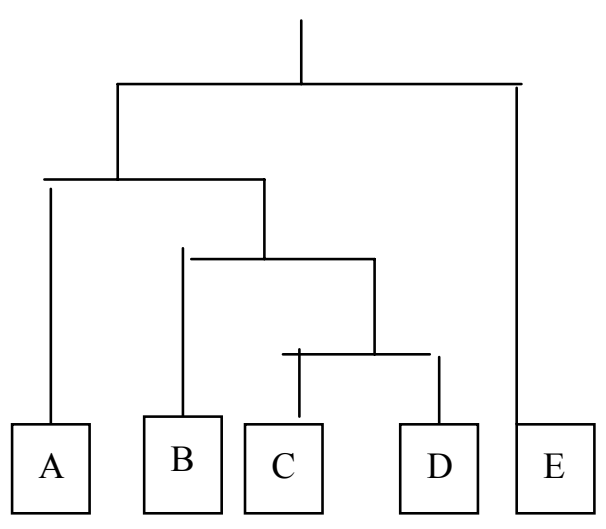

Figure 2.

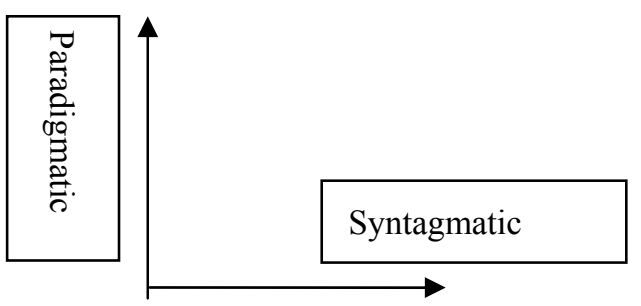

Figure 3.

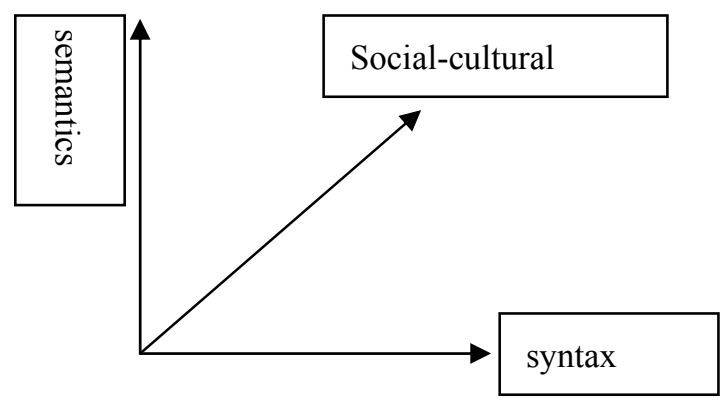

Figure 4

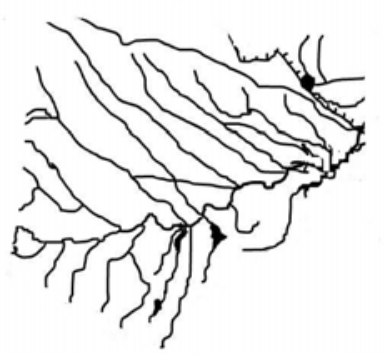

Figure 5 